\title{
A Simple Theory of Smart Growth and Sprawl
}

\author{
Matthew A. Turner \\ Department of Economics \\ University of Toronto \\ 150 St. George Street \\ Toronto, Canada M5S 3G7 \\ mturner@chass . utoronto.ca
}

January 2006

\begin{abstract}
This paper considers the simultaneous determination of residential density and the supply of local versus remote retail services. Possible equilibrium development patterns either correspond closely to what anti-sprawl activists describe as smart growth, or to its opposite. Equilibrium and optimal patterns of development do not always coincide. When equilibrium and optimal patterns of development diverge, optimal density is always discretely (as opposed to marginally) higher than equilibrium density. This occurs in the absence of congestion externalities, and is due to a free-rider problem and a coordination problem. The analysis indicates that a tax on large lots or a subsidy for small lots may be welfare improving under certain conditions.
\end{abstract}

KEYWORDS: urban sprawl, residential land use, lot size, retail location, urban economics. J.E.L.: R2, H0. 


\section{Introduction}

Pedestrian based neighborhoods in which people live on small lots at relatively high densities and are able to walk to nearby stores are the grail of lobby groups opposed to urban sprawl. ${ }^{1}$ Conversely, neighborhoods where people live on large lots and drive for all of their daily errands are anathema to these lobbies. To understand the economic forces that lead to one type of neighborhood or the other, this paper develops a model in which the location of housing and retail services are simultaneously determined, and investigates both equilibrium and optimal patterns of retail and residential location.

Beyond its relevance to the ongoing debate over urban sprawl, this analysis is of interest for three reasons. First, the preponderance of the existing theoretical literature on the structure of cities is based on the Mills-Muth model of a monocentric city and its generalizations (e.g., Brueckner (4) and Berliant and Fujita (2)). This model focuses on the cost of commuting to work as the force behind patterns of residential development. However, according to the National Household Transportation Survey (14), fewer than 30\% of an average American's daily trips are work related. Thus, it is of interest to develop models which allow us to analyze the relationship between nonwork trips and patterns of residential land use. This is precisely what is undertaken here.

Second, there is preliminary empirical evidence for a development process in which neighborhoods lock into either low or high density development patterns, but not into an intermediate density. The analysis presented here suggests an explanation for this observation.

Finally, this paper helps to explain an apparent gap between anti-sprawl activists and urban economists. Anti-sprawl activists are apt to describe 'urban sprawl' hyperbolically, e.g., "We drive up and down the gruesome, tragic suburban boulevards of commerce, and we're overwhelmed at the fantastic, awesome, stupefying ugliness ..." (Kuntsler (12)). More prosaically, anti-sprawl activists seem to think that the organization of many current urban landscapes is not slightly, or marginally different from the optimum, they think it is fundamentally wrong. Urban economists on the other hand, appear to be more sanguine and advocate marginal changes, like congestion taxes and marginal cost pricing for infrastructure, e.g., Brueckner (3). The analysis in this paper provides a basis for resolving this apparent conflict. More specifically, this paper provides a framework in which we can identify the conditions under which fundamentally wrong development patterns can and cannot emerge.

This paper considers the simultaneous determination of residential density and the supply of local versus remote retail services. It takes as given the availability of a remote retail sector to anyone willing bear the cost of driving to it, and considers the entry decision of a local retailer, along with decision of immigrants to locate in a neighborhood on small or large lots. Large lots provide utility to their owners, but serve to reduce the number of people in the neighborhood. The local retailer (e.g., a small grocery store, cafe or bookstore) can be reached by foot by neighborhood residents. The local retailer can only survive if it operates at a certain minimum scale, and this scale can only be achieved if the neighborhood is occupied by residents who choose small lots.

\footnotetext{
${ }^{1}$ I am grateful for financial support from SSHRC. I am also grateful to Simon Board, Jan Brueckner, Gilles Duranton, William Strange, and two anonymous referees for helpful comments and discussions.
} 
Possible equilibrium development patterns either correspond closely to what anti-sprawl activists describe as smart growth, or to its opposite. Equilibrium and optimal patterns of development do not always coincide. When equilibrium and optimal patterns of development diverge, optimal density is always discretely (as opposed to marginally) higher than equilibrium density. This occurs in the absence of congestion externalities, and is due to a free-rider problem and a coordination problem. The analysis indicates that a tax on large lots or a subsidy for small lots may be welfare improving under certain conditions.

\section{Related literature}

The object of this analysis is to consider patterns of residential location and land consumption in a model where retail location is simultaneously determined with decisions about residential location and housing density. While this issue has not been addressed directly, a number of different strands of literature are relevant.

A large literature investigates city structure when there are agglomeration externalities in production, and firm and residential locations are endogenous. In this literature, it is possible that 'edge cities', small subcenters on the periphery of a large center, arise in equilibrium. These subcenters look much like the neighborhoods studied here, and coordination problems similar to those described here can also arise in these models. These models differ from the one in this paper in that they are principally interested in patterns of location for employers, and as a simplifying assumption, they generally fix lot sizes for urban residents. This literature is surveyed in Duranton and Puga (7).

An exception is Helsley and Strange (10). Helsley and Strange (10) consider a model where individuals travel to the city center in order to engage in social interactions whose value increases with the number of other individuals present in the center. Since they allow residential location and density to be endogenously determined, their model has many features in common with the one considered here. Helsley and Strange (10), however, are interested in the provision of a public good, 'social interactions', while I am interested in the provision of a private good, 'retail services'. In addition, my model is intended to explain the structure of a single neighborhood at the edge of an existing city, while Helsley and Strange (10) are interested in explaining the structure of a whole city.

There is also a literature on the formation of neighborhoods in an environment with endogenous provision of local public goods, endogenous location of individuals, and endogenous land consumption. This large literature is surveyed in Scotchmer (15). While the present analysis may appear similar to the literature on local public goods, it actually considers the provision of a private good, retail services, a problem which by definition is not addressed by the literature on local public goods. In particular, since retail services are provided by the private sector there is no need to investigate a tax regime for financing these services, an important topic for the literature on local public goods.

In Chapter 7 of their excellent book, Fujita and Thisse (8) survey the literature on the location of retail firms with a view to understanding the forces that cause retail firms to agglomerate. To the 
extent that residential location is endogenized in these models, it is done under the assumption of fixed lot size. Thus, while the literature surveyed in Fujita and Thisse (8) teaches us about the emergence of business districts, it does not allow an investigation of the relationship between housing density and the organization of the retail services market. In another excellent book, DiPasquale and Wheaton (6) describe patterns of retail and population location in greater Boston and survey the theoretical literature. Like Fujita and Thisse (8), the review of theoretical literature in DiPasquale and Wheaton (6) focuses on the implications of retail firm location for the location decisions of other retail firms.

Perhaps the closest competitor to this paper is Berliant and Konishi (1). Berliant and Konishi (1) rationalize the emergence of cities and systems of cities as trading centers. They consider a general equilibrium model of market and residential location in an environment with a discrete set of possible residential locations, endogenous land consumption, and different technologies for transport to 'near' and 'far' markets. By contrast, the current paper considers a partial equilibrium model of the formation of neighborhoods on the edge of an existing city, and is interested in the implications of a minimum scale requirement for retail firms on patterns of residential development.

Finally, in Turner (16) I analyze a model superficially similar to the one considered here. In particular, Turner (16) considers the implications of a taste for nearby public open space on the resulting equilibrium and optimal organization of residential land. Given a taste for public open space, residents impose a cost on their neighbors by depriving them of open space. With market allocation of land, this cost is not priced and leads the competitive organization of residential land to be denser than the optimum. The current paper addresses the opposite situation, one in which neighborhood residents can benefit from having an additional neighbor.

\section{A retail and residential development game}

I consider the development of a new residential neighborhood at the edge of an existing city. I would like to understand the forces which determine whether this neighborhood is developed at a high density with retail stores within walking distance of most residences, or at low density with residents driving for all retail services.

To begin, consider a city that is in equilibrium until just before the analysis begins, at which time local wages increase exogenously. Migration to the city occurs in response to this increase in the local wage, and immigrants have the choice of a location in the neighborhood under study or in some other city or neighborhood. I consider new development that occurs in a neighborhood at the city's edge to house the new arrivals.

For integer $N>0$, let $Y=\{1, \ldots, 2 N\}$ denote the set of available parcels of land and $y \in Y$ a particular parcel. Each location is owned by a landlord, each of whom owns exactly one parcel. Index landlords by $y \in Y$ where a landlord's name also gives the name of his parcel. Let the set of potential immigrants be $I=\{1, \ldots, M\}$ with $M>2 N$. Let $i$ index this set. Potential immigrants must choose between locating in the area described by $Y$ or another location $\theta$, implicitly some other city or neighborhood. If immigrants choose to locate in $Y$ they must occupy at least one parcel, but may choose to occupy two parcels. More formally, immigrant i's choice of location, $\mathbf{y}_{i}$, 
is a set $\left\{y, y^{\prime}\right\}$ if he chooses a double lot, a singleton $\{y\}$ if he chooses a single lot, and $\theta$ if he chooses the alternate city. Let $i(y)$ denote the immigrant(s) occupying parcel $y$, with $i(y)=\phi$ if $y$ is unoccupied. Let $X$ denote a location profile, the collection of all occupied locations in $Y$, and $X_{-i}$ the set of locations in $Y$ occupied by all immigrants excluding $i$.

Each landlord chooses a non-negative price for his land, $p_{y}$. If no immigrant chooses a landlord's location then the landlord receives the prevailing price in the best non-residential land use. To lighten notation, normalize this price to zero. Let $P=\left\{p_{1}, \ldots, p_{2 N}\right\}$ denote a choice of price for all landlords, and $P_{-y}=P / p_{y}$, a choice of price for all landlords but $y$.

All immigrants pay whatever price is associated with their choice of lot and all immigrants commute into the old city to work for wage $w \in \mathcal{R}_{++}$. Immigrants are averse to sharing a location, and if two immigrants occupy the same parcel they receive a large negative payoff. Immigrants who choose location $\theta$ get reservation utility level $u_{\theta} \in \mathcal{R}_{++}$. Immigrants have a taste for large lots and receive a utility bonus $\delta \in \mathcal{R}_{++}$if they occupy two parcels rather than one. This utility bonus may be interpreted in two ways. First, that immigrants derive utility directly from having more land. Alternately, a larger lot allows immigrants to substitute away from capital in their production of housing and increases utility indirectly through this channel. To simplify the analysis there is no utility bonus from additional parcels beyond two.

All immigrants consume one unit of retail services. Retail services are always available from a remote retailer for a cost $t_{D} \in \mathcal{R}_{++}$which is the sum of the cost of driving to the remote retailer and the price of remote retail services. Retail services may also be available locally at a cost $t_{W}+q$, where $t_{W} \in \mathcal{R}_{++}$is the parcel invariant cost of walking to the local retailer and $q \in \mathcal{R}_{++}$is the unit price of retail services at this local retailer. Conditional on choosing a lot in $Y$ and on the presence of a local retailer, an immigrant must choose whether to walk or drive to purchase retail services.

Formally, an immigrant's payoff can be written,

$$
u_{i}\left(\mathbf{y}_{i}, p_{y_{i}}, X_{-i}\right)= \begin{cases}w-\left(p_{y_{i}}+p_{y_{i}^{\prime}}\right)+\delta-t_{D} & \text { if } i \text { chooses a double lot and driving } \\ w-\left(p_{y_{i}}+p_{y_{i}^{\prime}}\right)+\delta-\left(t_{W}+q\right) & \text { if } i \text { chooses a double lot and walking } \\ w-p_{y_{i}}-t_{D} & \text { if } i \text { chooses a single lot and driving } \\ w-p_{y_{i}}-\left(t_{W}+q\right) & \text { if } i \text { chooses a single lot and walking } \\ -\infty & \text { if immigrants purchase more than } 2 N \text { parcels } \\ u_{\theta} & \text { if } y_{i}=\theta .\end{cases}
$$

Note that if immigrants purchase more than $2 \mathrm{~N}$ parcels, at least two immigrants will share a parcel. Therefore, the effect of assigning an infinite penalty to profiles where immigrants occupy more than $2 \mathrm{~N}$ parcels is to prohibit equilibria where immigrants share a parcel.

If a local retailer locates in the neighborhood, he pays a fixed cost of $F$ and no marginal cost. Thus, conditional on entry, profits for the local retailer are $\pi=n q-F$, where $n$ denotes the number of immigrants in the neighborhood. If the local retailer does not enter his profits are zero. Formally, an action for the local retailer is $E \in\{E n t e r, N o t\}$. In order for the problem to be non-trivial, assume that $t_{W}+q<t_{D}$, so that immigrants always choose to shop locally if a retailer enters. Also assume that $2 N q>F>N q$, so that the local retailer is profitable if and only if some portion of $Y$ is occupied by immigrants on single lots. 
To simplify the exposition the local retailer does not consume land. This is consistent with the presence in each neighborhood of parcels suitable for retail development but not for residential development, e.g., parcels near a busy street corner or railroad tracks. With this said, relieving retailers from purchasing land is a simplifying assumption made to facilitate welfare comparisons between neighborhoods with and without a local retailer. Requiring that a local retailer purchase land does not qualitatively change my results.

The local retailer is assumed to charge an the exogenously determined unit price, $q$, rather than choosing a price to maximize profits. This assumption eliminates the need for a pricing game. Since equilibria of such games depend sensitively on assumptions about market structure and the possibility of entry (Mas-Collel, Whinston and Green (13)), endogenizing $q$ would lead to a model in which results depend sensitively on assumptions made about the monopolistic pricing game. For my purpose, what is important is how much rent the monopoly local retailer is able to extract from each immigrant. Leaving $q$ exogenous permits comparative statics on this price.

To complete the model it remains to describe the timing of moves and the operation of the land market. The market for residential land operates in three stages. First, all landlords simultaneously choose prices. Second, the local retailer and all immigrants simultaneously decide whether or not to locate in $Y$, and all immigrants simultaneously choose their lots and pay for the component parcels. In the third stage, immigrants decide whether to walk to the local retailer or drive to the remote retailer. ${ }^{2}$

All agents are restricted to choose pure strategies. A strategy for a landlord is a mapping from the set of price profiles into the set of non-negative real numbers. That is, $S_{y}\left(P_{-y}\right)=p_{y}$. A strategy for an immigrant is a mapping from an observed price and location profile into the set of possible lots, i.e., $S_{i}\left(P, X_{-i}, E\right) \in\{Y \times Y\} \cup\{\theta\}$. Since $t_{W}+q<t_{D}$, immigrants always purchase retail services from the local retailer if he enters. A strategy for the local retailer is a mapping from observed price and location profiles into $\{$ Enter, Not $\}$, i.e., $E=S_{R}(P, X) \in\{$ Enter, Not $\}$. Let $\left(P^{*}, X^{*}, E^{*}\right)$ denote a subgame perfect equilibrium choice of prices, lots, and entry. Landlords who fail to attract an immigrant are assumed to choose price zero in any equilibrium. This assumption replaces an implied fourth stage of the game in which landlords rent their land to a class of residual users.

\section{Equilibrium patterns of retail and residential development}

An equilibrium of the retail and residential development game determines: population density, land prices, the presence or absence of a local retailer, and shopping patterns. The model takes as exogenous: utility levels for the alternative neighborhood, a price for the local retailer, transportation costs to local and remote retailers, and a neighborhood specific large lot bonus and wage.

Figure 1 provides a summary of equilibrium patterns of residential and retail development. The horizontal axis in this figure gives the magnitude of $w-u_{\theta}$. This quantity is an immigrant's surplus from locating in neighborhood $Y$, gross of retail services and the large lot bonus. All else

\footnotetext{
${ }^{2}$ Note that the two-stage, 'Bertrand' operation of the land market is essential because it allows immigrants an opportunity to respond to a landlord's price deviations. Without such an opportunity, unilateral price changes could not have an effect on immigrant location choices.
} 
equal, as we move to the right along this axis neighborhood $Y$ becomes more attractive relative to the next best alternative. If we think of $w$ as the wage net of the cost of commuting from the neighborhood to the nearest employment center then increases in $w$ can reflect changes in worker productivity or changes in commute distance. Given this, I interpret an increase in $w-u_{\theta}$ as a decrease in the distance from $Y$ to an employment center. ${ }^{3}$ The vertical axis in figure 1 gives the magnitude of the large lot bonus. All else equal, as we move vertically along this axis, a large lot becomes more valuable in neighborhood $Y$. Loosely, a neighborhood is more attractive as its distance from the origin increases.

Three patterns of retail and residential development are possible in equilibrium, vacant, low density and high density. In a vacant equilibrium, no immigrants locate in $Y$. In a low density equilibrium $N$ immigrants locate on double lots in $Y$. In a high density equilibrium $2 N$ immigrants locate on single lots in $Y$. The local retailer enters if and only if the neighborhood is occupied at high density. Land prices adjust so that immigrants are indifferent between neighborhood $Y$ and the alternative location $\theta$, if neighborhood $Y$ is not vacant.

Figure 1 divides the parameter space into five regions and describes the possible equilibria in each region. The remainder of this section discusses figure 1 in detail and provides a complete characterization of the equilibria.

Neighborhoods in region 1 are sufficiently remote from employment centers and the land is sufficiently unattractive or unproductive in housing that no immigrant wants to locate in these neighborhoods. Region 1 is described by two constraints. The first constraint, $w-t_{D}+\delta<u_{\theta}$, requires that if the local retailer does not enter then an immigrant prefers $\theta$ to a free double lot in $Y$. Therefore, if the local retailer does not enter, this neighborhood cannot attract immigrants. The left hand side of the constraint $w-u_{\theta}-\left(t_{W}+q\right)<\delta$ gives the upper bound on the price that an immigrant can pay to occupy a single lot in $Y$, shop at a local retailer and still not have an incentive to deviate to $\theta$. The inequality requires that this amount be less than the open space bonus. Thus this constraint requires that, if the local retailer enters and immigrants occupy single lots then the price of land is less than the open space premium so that immigrants will consolidate single lots into double lots. Together these two constraints require that a neighborhood in region 1 cannot support the necessary density to make a retail firm profitable and that without a retail store the neighborhood cannot attract immigrants, even to free double lots. Since neither high density nor low density development is an equilibrium, a neighborhood in region 1 must be vacant. Proposition 1 formalizes this intuition. The proof of this proposition, and others that follow, is presented in a technical appendix.

Proposition 1 If $w-u_{\theta}-\left(t_{W}+q\right)<\delta$ and $w-t_{D}+\delta<u_{\theta}$ then a pattern of retail and residential location is a subgame perfect equilibrium outcome if and only if all immigrants choose $\theta$ and the local retailer does not enter.

A neighborhood in region 2 is too far from an employment center to support dense residential housing but the land is attractive enough that people are willing to live there on large lots and drive to a remote retailer. Region 2 in figure 1 is described by two constraints. The constraint

\footnotetext{
${ }^{3}$ Other factors may also increase the magnitude of $w-u_{\theta}$. For example, an increase in the quality of local amenities.
} 


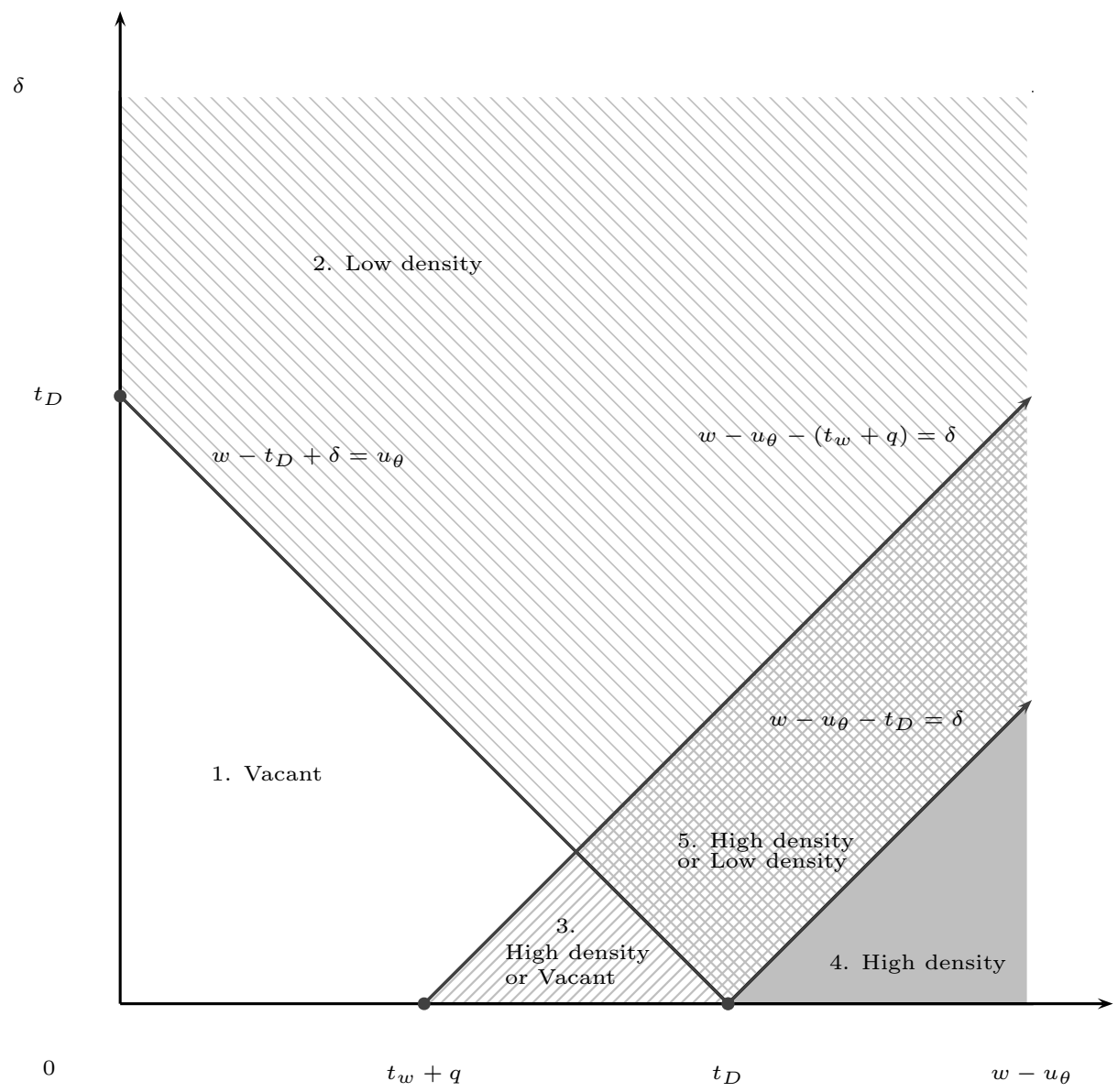

Figure 1. Possible equilibrium retail and residential development patterns in different regions of the parameter space.

$w-t_{D}+\delta>u_{\theta}$ requires that neighborhood $Y$ be attractive enough that an immigrant prefers a free double lot in neighborhood $Y$ to $\theta$. Thus, $Y$ cannot be vacant in equilibrium. The constraint $w-u_{\theta}-\left(t_{W}+q\right)<\delta$ is carried over from region 1 . It requires that if the local retailer enters and immigrants occupy single lots then the open space premium is large enough that immigrants have an incentive to consolidate single lots into double lots. Thus, no residential development pattern where the local retailer enters and immigrants occupy single lots can be an equilibrium. In all, for a neighborhood in region 2, equilibrium requires that immigrants live on double lots and that the local retailer not enter. Proposition 2 provides a formal statement of this result.

Proposition 2 If $w-u_{\theta}-\left(t_{W}+q\right)<\delta$ and $w+\delta-t_{D}>u_{\theta}$ then an outcome of the retail and residential development game is a subgame perfect equilibrium if and only if $N$ immigrants occupy double lots in $Y$, the price of all lots is $p_{y}=\frac{1}{2}\left(w-u_{\theta}-t_{D}+\delta\right)$, and the local retailer does not enter.

A neighborhood in region 3 occupies land just close enough to an employment center that immigrants are willing to live there on single lots only if a local retailer enters. However, the land is not so attractive that a double lot can compensate immigrants for the absence of a local retailer. Thus, immigrants are willing to live on single lots if and only if the local retailer enters and do not occupy the neighborhood otherwise. This region of figure 1 is described by two constraints. The constraint $w-u_{\theta}+\delta<t_{D}$ restricts attention to neighborhoods where immigrants prefer $\theta$ to a free 
double lot when the local retailer does not enter. The second constraint, $w-u_{\theta}-\left(t_{W}+q\right)>\delta$, requires that if the local retailer enters and immigrants occupy single lots then the open space premium is not so large that immigrants have an incentive to consolidate single lots into double lots. Thus two possible arrangements can arise in equilibrium. In the first, neighborhood $Y$ is vacant and the local retailer does not enter. In the second, neighborhood $Y$ is densely occupied and the local retailer enters. For neighborhoods in region 3 realized development patterns hinge on the resolution of a coordination problem. Immigrants choose single lots in the neighborhood if and only if the local retailer enters. Otherwise the local retailer and immigrants prefer not to enter neighborhood $Y$ at all. Proposition 3 formalizes this intuition.

Proposition 3 If $w-u_{\theta}>\delta+\left(t_{W}+q\right)$ and $w-u_{\theta}+\delta<t_{D}$ then an outcome of the retail and residential development game is a subgame perfect equilibrium if and only if:

1. All immigrants choose $\theta$ and the local retailer does not enter, or,

2. $2 N$ immigrants occupy single lots in $Y, p_{y}=w-u_{\theta}-\left(t_{W}+q\right)$ for all $y$ in $Y$, and the local retailer enters.

A neighborhood in region 4 of figure 1 is one that is so close to an employment center that land is too valuable for large lots to occur in equilibrium. This region of figure 1 is described by the single constraint $w-u_{\theta}-t_{D}>\delta$. The left hand side of this constraint describes the most that an immigrant would pay to occupy a single lot in $Y$ when the local retailer does not enter. The right hand side is the amount that an immigrant will pay for a second lot. Given this, vacant lots will always be occupied by immigrants from $\theta$, and an immigrant from $\theta$ has an incentive to outbid an immigrant in $Y$ for his second lot. Thus, the only possible equilibrium occurs when $Y$ is populated by immigrants on single lots. Given this, the local retailer can make a profit by entering. Proposition 4 formalizes this intuition.

Proposition 4 If $w-u_{\theta}-\delta>t_{D}$ then an outcome of the retail and residential development game is a subgame perfect equilibrium if and only if $2 \mathrm{~N}$ immigrants occupy single lots in $Y, p_{y}=w-u_{\theta}-\left(t_{W}+q\right)$ for all $y$ in $Y$, and the local retailer enters.

Like neighborhoods in region 3, development in neighborhoods in region 5 hinges on the resolution of a coordination problem. A neighborhood in region 5 is just close enough to an employment center that immigrants are willing to live there on single lots only if a local retailer enters. However, the land is attractive enough for housing that a large lot is able to compensate an immigrant for the absence of a local retailer. Thus, immigrants are willing to live on single lots if and only if the local retailer enters and occupy the neighborhood at low density otherwise. Region 5 of figure 1 is described by three constraints. The left hand side of the constraint $w-u_{\theta}-t_{D}<\delta$ describes the most that an immigrant would pay to live in neighborhood $Y$ on a single lot without access to a local retail store. That this amount is less than $\delta$ assures that if the local retailer does not enter and $Y$ is occupied by immigrants on double lots then these immigrants will not be outbid for their second lots by immigrants from $\theta$. The left hand side of the constraint $w-u_{\theta}-\left(t_{W}+q\right)>\delta$ describes the most that an immigrant on a single lot would be willing to pay to locate in $Y$ given 
entry by a local retailer. This constraint assures that if a local retailer enters then immigrants from $\theta$ outbid any immigrant on a double lot for their second lot. The third inequality, $w-t_{D}+\delta>u_{\theta}$, states that even if the local retailer does not enter, an immigrant prefers a free double lot in $Y$ to $\theta$. Altogether these constraints allow for two types of equilibria. In one the immigrants occupy double lots and the local retailer does not enter. In the other immigrants occupy single lots and the local retailer enters. Which of these two patterns is observed depends on how the immigrants and the local retailer resolve their coordination problem. Proposition 5 formalizes this intuition.

Proposition 5 If $w-u_{\theta}-t_{D}<\delta, w-u_{\theta}-\left(t_{W}+q\right)>\delta$ and $w-u_{\theta}+t_{D}>\delta$ then an outcome of the retail and residential development game is a subgame perfect equilibrium if and only if:

1. N immigrants occupy double lots in $Y, p_{y}=\frac{1}{2}\left(w-u_{\theta}-t_{D}+\delta\right)$ for all $y$ in $Y$, and the local retailer does not enter, or,

2. $2 N$ immigrants occupy single lots in $Y, p_{y}=w-u_{\theta}-\left(t_{W}+q\right)$ for all $y$ in $Y$, and the local retailer enters.

In summary, this analysis shows that in much of the parameter space described by figure 1 the model of retail and residential development behaves in familiar ways. Near the origin, the least attractive part of the parameter space, equilibrium requires that neighborhoods be vacant. In the region 'due east' of the origin, where the surplus from locating in $Y$ is large and the large lot bonus is small, we see only high density development. In the 'northern' part of the parameter space, where the value of a second lot is large but the surplus from occupying a parcel is not otherwise large, only low density development is possible.

Regions 3 and 5 are more interesting. In these regions more than one equilibrium outcome is possible, one at high density and the other low density or vacant. In these regions, the realized development pattern depends on which equilibrium the various economic actors coordinate upon. The possibility of multiple equilibria has three interesting implications. First, one of these equilibria will generally not be socially optimal. Second, the equilibria are qualitatively different from each other. This raises the possibility that these neighborhoods may develop in a way that is qualitatively different from the optimum. Third, this non-optimality arises in a model where none of the usual precursors of urban sprawl are present: road congestion does not occur, infrastructure is correctly priced, there are no distortionary taxes. Thus, if a neighborhood does manage to coordinate on a bad equilibrium, the usual corrective taxes will not solve the problem.

Before moving on to a welfare analysis, it is of interest to consider whether the intuition generated by this model is robust to generalization of the various simplifying assumptions. Three features of the model appear to be essential to preserving qualitatively similar results. First, the local retailing sector cannot be too inefficient relative to the remote retailing sector. If immigrants always prefer to drive to the remote retailer, then they are never willing to forgo a large lot in order to gain access to a local retailer and high density development cannot occur in equilibrium. Second, the local retailer must be subject to increasing returns to scale. In the model considered here this assumption is made in its starkest possible form: the local retailer cannot exist below some minimum scale. The presence of 'sufficiently strong' increasing returns to scale in the local retailing 
sector is required if we are to have multiple equilibrium. It is not necessarily required that the technology take the deliberately simple form used here. Third, and finally, the intuition developed here relies on the fact that landlords are small relative to the minimum scale required to support a local retailer. With the presence of increasing returns to scale in local retailing, immigrants impose external benefits on each other. A sufficiently large landlord can internalize these external benefits and capitalize them into land rents. The assumption of 'very small' landlords is made to simplify the analysis. Relaxing this assumption does not appear to qualitatively affect the workings of the model, provided that landlords remain small relative to the minimum scale of the local retailer.

On the other hand, extensions of the model to heterogenous populations and more elaborate preferences over land come at great cost in complexity, and while they increase the realism of the model they do not appear to lead to any further intuition about the problem.

It may also be of interest to consider variants of the game in which the timing of moves is different. Many such sequences are possible, e.g., the local retailer makes its entry decision before landlords choose prices, the local retailer makes its entry decision before immigrants choose locations but after land owners choose prices, the local retailer makes its entry decision after immigrants choose locations. General statements about the implications of changes to the sequence of play for the results provided here are beyond the scope of this paper. However, preliminary analysis suggests that allowing immigrants to move before the local retailer does not qualitatively change the results. On the other hand, allowing the local retailer to move before the immigrants may help to resolve the coordination problem, although it is not clear that we ought to regard this formulation as reasonable since it requires that the local retailer commit to stay in the neighborhood even if the residential location pattern assures that the retailer is not profitable.

\section{Optimum patterns of retail and residential development}

To measure the welfare level of a given development pattern I sum rent that accrues to neighborhood land, to the local retailer, and the change in rent that remote retailer experiences as a result of location patterns in neighborhood $Y$. This quantity represents the most that immigrants, landowners and retailers would pay, in aggregate, to have neighborhood $Y$ opened up to immigration.

Clearly, the possibility of increasing returns to scale in the remote retailing sector is of fundamental importance to the welfare analysis. If the cost of remote retail services is consumed entirely in transportation the welfare analysis is quite different than if $t_{D}$ consists entirely of monopoly rent captured by the remote retailer. Likewise, if there is increasing returns to scale in the remote retailing sector then allowing a local retailer in neighborhood $Y$ could be harmful to residents of other neighborhoods who are thereby deprived of less costly remote retail services. Indeed, if the remote retailing sector is subject to 'strong enough' increasing returns to scale, dense neighborhoods with local retail are never optimal.

With this said, examining the implications of different sorts of technological structures for the optimal citywide portfolio of local and remote retailing is beyond the scope of the current analysis. Therefore, I consider particularly simple local and remote retailing technologies in order to abstract from these issues. 
In particular, assume that $t_{D}$ consists entirely of transportation costs. Implicitly, this assumption also requires that the remote retailer produces retail services at zero marginal cost, and that the remote retailer operates in a competitive environment. Furthermore, recall that I earlier specified a very simple local retail technology: after paying his fixed cost to locate in $Y$ the local retailer produces retail services at zero marginal cost. Thus, $q$ is a pure monopoly rent and $t_{W}$ is pure travel costs. Given these assumptions, monopoly rents for the remote retailer are zero, while monopoly rents for the local retailer are $n q-F$ if the local retailer enters and zero otherwise.

For a given pattern of development, let $N_{H}$ denote the number of immigrants locating in $Y$ on single lots and let $N_{L}$ denote the number of immigrants locating in $Y$ on double lots. The planner's problem is to arrange immigrants across single lots, double lots, and $\theta$, and to choose whether or not the local retailer enters, so as to maximize the sum of land rents and rent for the local retailer.

To begin, consider a constrained version of this problem where the local retailer cannot enter. The land rent generated by a particular parcel is the most that an immigrant would pay for the opportunity to locate on that parcel. That is, $w-u_{\theta}$ adjusted by the cost of retail services and possibly an open space bonus. Let $W_{D}$ denote aggregate land rent when the local retailer does not enter and all immigrants drive to a remote retailer. Recalling there are $M$ immigrants in total, the planner's constrained maximization problem is given by,

$$
\begin{array}{cl}
W_{D}^{*}=\max _{N_{H}, N_{L}} & N_{H}\left(w-u_{\theta}-t_{D}\right)+N_{L}\left(w-u_{\theta}-t_{D}+\delta\right)+M u_{\theta} \\
\text { s.t. } & N_{H}+2 N_{L} \leq 2 N \\
& N_{H}, N_{L} \geq 0 .
\end{array}
$$

To solve this problem, note that the objective function is linear in the choice variables. Thus, in general, only one type of land use will occur in any optimum, high density, low density, or vacant. Which of these three uses is optimal is determined by the magnitudes of the objective when all land is assigned to each of these three classes. A little algebra shows that the solution to this problem is,

$$
W_{D}^{*}= \begin{cases}M u_{\theta} & \text { if } w-u_{\theta}-t_{D}<-\delta \\ N\left(w-u_{\theta}-t_{D}+\delta\right)+M u_{\theta} & \text { if }-\delta<w-u_{\theta}-t_{D}<\delta \\ 2 N\left(w-u_{\theta}-t_{D}\right)+M u_{\theta} & \text { if } \delta<w-u_{\theta}-t_{D} .\end{cases}
$$

In words, from the top of the parenthetical list to the bottom, when the local retailer does not enter constrained optimality requires that: $Y$ be vacant when $w-u_{\theta}-t_{D}<-\delta$, that $Y$ be occupied entirely at low density when $-\delta<w-u_{\theta}-t_{D}<\delta$, that $2 N$ immigrants occupy $Y$ at high density when $w-u_{\theta}-t_{D}>\delta$. Figure 2 illustrates this solution and shows that optimizing behavior is intuitive. When $w-u_{\theta}$ and $\delta$ are small $Y$ is vacant. When $w-u_{\theta}$ is larger and the large lot bonus is still small then $Y$ is occupied at high density. When the large lot bonus is large $Y$ is occupied at low density.

We can also solve the corresponding constrained optimization when the local retailer must enter. Let $W_{W}$ denote aggregate land rent when the local retailer does enter and all immigrants walk to a local retailer. Then the planner's constrained maximization problem is given by, 


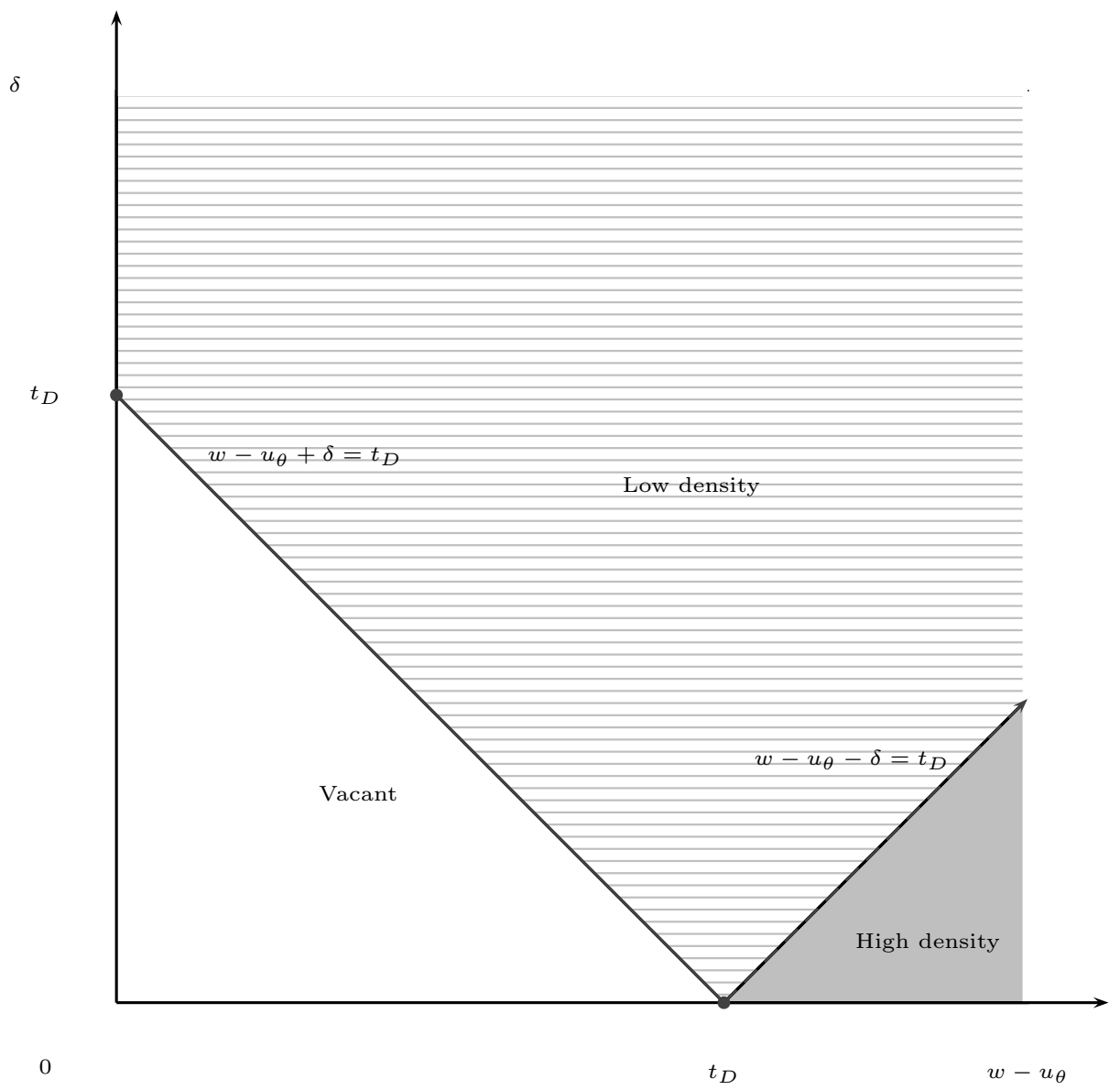

Figure 2. Socially optimal types of residential development given that the local retailer is constrained not to enter.

$$
\begin{aligned}
W_{W}^{*}=\max & N_{H}\left(w-u_{\theta}-t_{W}\right)+N_{L}\left(w-u_{\theta}-t_{W}+\delta\right)-F+M u_{\theta} \\
\text { s.t. } & N_{H}+2 N_{L} \leq 2 N \\
& N_{H}, N_{L} \geq 0 .
\end{aligned}
$$

The form of this problem is the same as when the local retailer is constrained not to enter. By a similar calculation the solution to this problem is,

$$
W_{W}^{*}= \begin{cases}M u_{\theta}-F & \text { if } w-u_{\theta}-t_{W}<-\delta \\ N\left(w-u_{\theta}-t_{W}+\delta\right)+M u_{\theta}-F & \text { if }-\delta<w-u_{\theta}-t_{W}<\delta \\ 2 N\left(w-u_{\theta}-t_{W}\right)+M u_{\theta}-F & \text { if } \delta<w-u_{\theta}-t_{W} .\end{cases}
$$

In words, from the top of the parenthetical list to the bottom, when the local retailer enters constrained optimality requires that: $Y$ be vacant when $w-u_{\theta}-t_{W}<-\delta$, that $Y$ be occupied entirely at low density when $-\delta<w-u_{\theta}-t_{W}<\delta$, that $2 N$ immigrants occupy $Y$ at high density when $w-u_{\theta}-t_{W}>\delta$. While optimizing behavior when the local retailer enters is qualitatively similar to optimizing behavior when the local retailer does not enter, two features of this optimum deserve comment. First, the price of retail services at the local retailer, $q$, does not appear in $W_{W}^{*}$. 


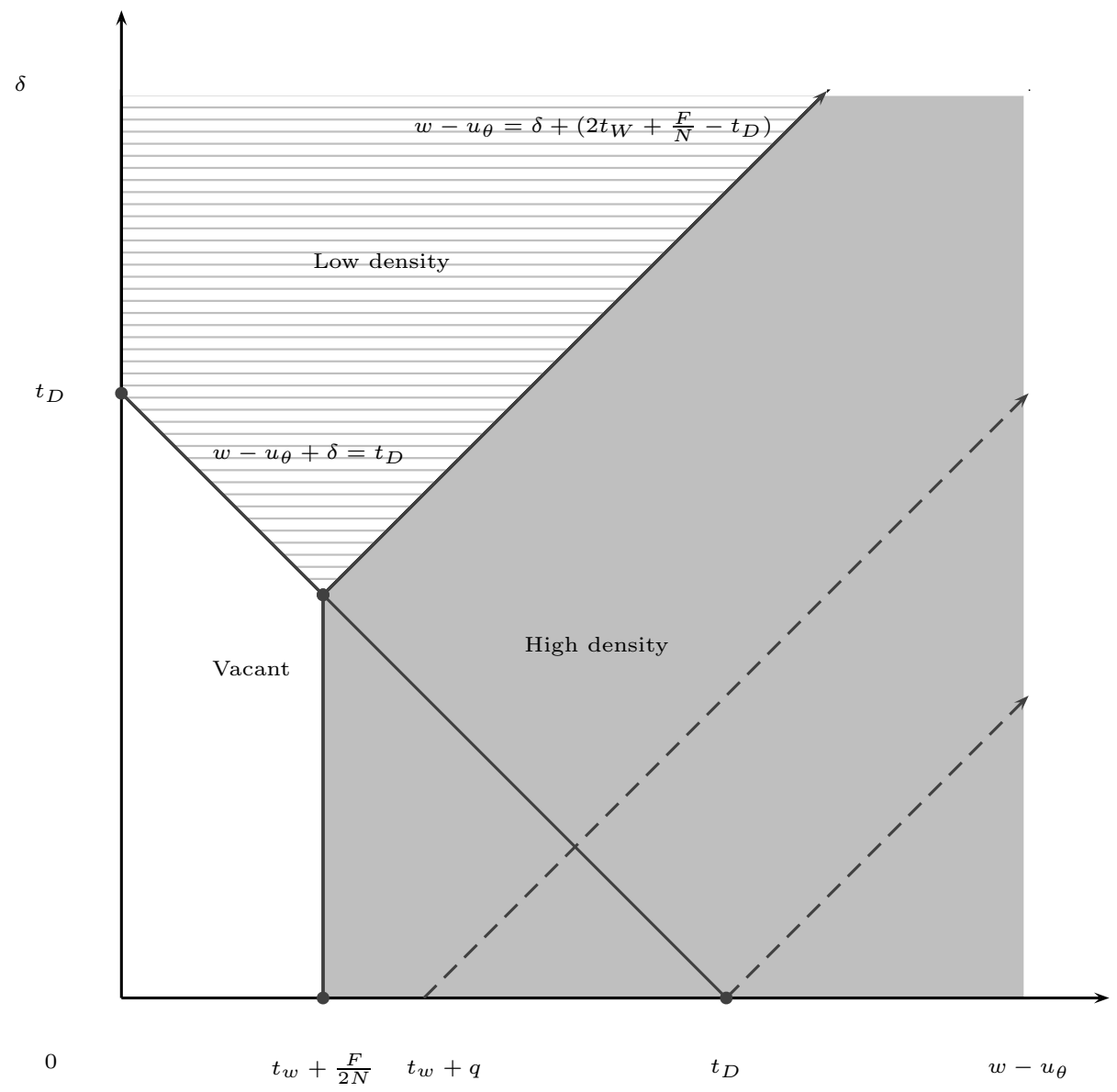

Figure 3. Socially optimal patterns of residential development.

Since the marginal cost of local retail services is zero, $q$ is just a transfer from immigrants to the local retailer and does not affect welfare. Second, the choice of density at which to develop $Y$ does not depend on $F$. When the local retailer is constrained to enter $F$ is a sunk cost which does not respond to these decisions.

To arrive at a solution to the unconstrained planner's problem, that is, the rent maximizing arrangement of immigrants and retailers, we must choose $W^{*}=\max \left\{W_{W}^{*}, W_{D}^{*}\right\}$. To proceed, first note that it is never optimal for the local retailer to enter when $Y$ is vacant. Second, while it can never occur in equilibrium, it may be that the optimum is for $Y$ to be occupied at low density when the local retail firm enters. For now, impose the parametric restriction, $N t_{W}+F>N t_{D}$, so that low density development with a local retailer is always dominated by low density development without a local retailer. Having eliminated vacant and low density neighborhoods with a local retailer as candidate optima, solving for $W^{*}$ now requires only that I compare $W_{D}^{*}$ with $2 N(w-$ $\left.u_{\theta}-t_{W}\right)+M u_{\theta}-F$, the rent obtained with high density occupation of $Y$ and entry by the local retailer. 
Performing this comparison I calculate the maximum possible welfare as,

$$
W^{*}=\left\{\begin{array}{lll}
M u_{\theta} & \text { if } w-u_{\theta}+\delta<t_{D} \\
& \text { and } w-u_{\theta}<t_{W}+\frac{F}{2 N} \\
N\left(w-u_{\theta}-t_{D}+\delta\right)+M u_{\theta} & \text { if } w-u_{\theta}+\delta>t_{D} \\
& \text { and } w-u_{\theta}-\delta<\left(2 t_{W}+\frac{F}{N}-t_{D}\right) \\
2 N\left(w-u_{\theta}-t_{W}\right)+M u_{\theta}-F & \text { if } w-u_{\theta}-\delta>\left(2 t_{W}+\frac{F}{N}-t_{D}\right) \\
& \text { and } w-u_{\theta}>t_{W}+\frac{F}{2 N} .
\end{array}\right.
$$

From the top of the parenthetical list to the bottom, optimality requires that $Y$ be vacant and the local retailer not enter, that $Y$ be occupied at low density and the local retailer not enter, and that $Y$ be occupied at high density and the local retailer enter. Figure 3 summarizes this result.

Comparing the unconstrained optimum of figure 3 with the constrained optimum of figure 2 shows that the difference between unconstrained and constrained optimization is intuitive. In the unconstrained optimum, the region of the parameter space where high density development occurs is unambiguously larger and encroaches on parts of the parameter space where the restricted optimal development pattern is low density or vacant.

This analysis so far has been based on a the parametric restriction $N t_{W}+F>N t_{D}$. The analysis is identical if we relax this assumption and simply prohibit the choice of low density development with entry by a local retailer. Since a local retailer will require a subsidy in a low density neighborhood this restriction converts our problem into the second best optimization problem in which the planner is prohibited from subsidizing the local retailer.

If we consider the complementary parameter restriction, $N t_{W}+F<N t_{D}$, then low density development with entry by the local retailer dominates low density development without entry by the local retailer. In this case, the figure corresponding to figure 3 changes only in that a portion of the parameter space where $Y$ is optimally vacant in figure 3 switches to low density development with local retail and the region of figure 3 given over to low density development without a local retailer switches to low density development with a local retailer.

\section{Optimal vs. equilibrium patterns of development}

There are three reasons why the equilibrium pattern of development differs from the optimum. First, in equilibrium immigrants respond to the market price of local retail services, $t_{W}+q$. This is different from the social price of these services, which is $t_{W}$ for the marginal immigrant and $t_{W}+\frac{F}{2 N}$ on average (given high density development). Second, when an immigrant decides whether to buy a second lot he does so purely on the basis of the difference between the value of a second parcel and the price of the parcel. He does not consider whether this decision will make a local retailer unprofitable. In effect, an immigrant who purchases a second lot is free riding on the fact that other immigrants facilitate the entry of the local retailer by living on single rather than double lots. Third, in some regions of the parameter space the choice of development pattern depends on the way that immigrants and the local retailer resolve a coordination problem. In these regions of the parameter space immigrants are willing to live at high density if and only if the local retailer enters. 


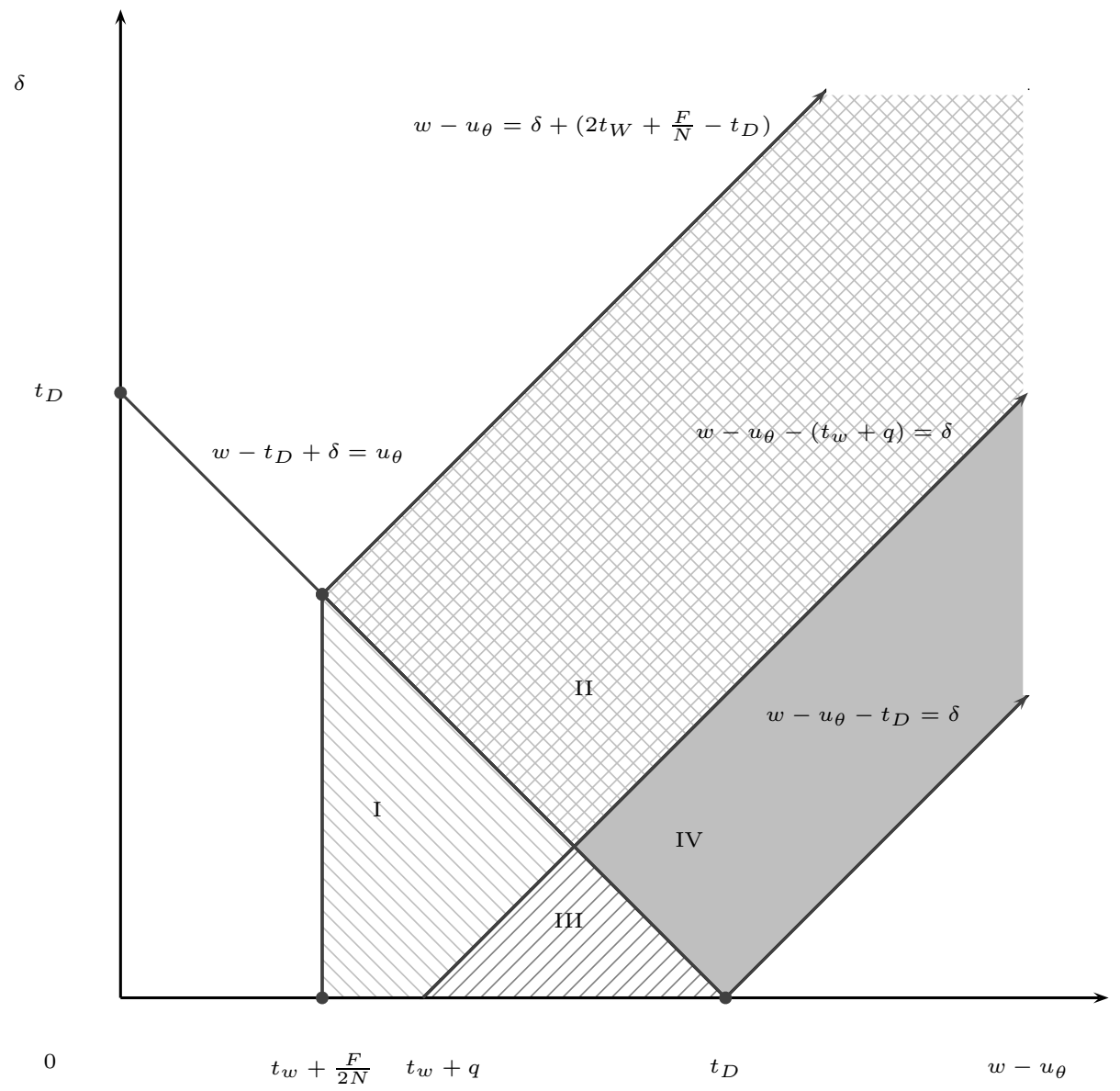

Figure 4. Shaded areas indicate regions of the parameter space where equilibrium and optimal patterns of retail and residential development diverge.

Figure 4 compares results presented by figures 1 and 3 to illustrate the differences between optimal and equilibrium patterns of development. Equilibrium and optimal development diverge in each of the four shaded regions of the graph and are identical in the white areas. In each of regions I-IV optimality requires high density development and entry by the local retailer. In equilibrium region I is vacant, region II is developed at low density without a local retailer, region III is either vacant or developed at high density with a local retailer, region IV is developed at low density without a local retailer or at high density with a local retailer.

In regions III and IV divergence between the equilibrium and the optimum is not certain. In these regions there are multiple equilibria and agents may coordinate on optimal or sub-optimal equilibria. Interestingly, in this context it makes sense to talk about high density development with a local retail sector as being 'smart' and low density car based development as 'sprawl'. Smart development patterns are those that result from a welfare maximizing resolution of the coordination problem. Sprawling development results from a sub-optimal resolution of the coordination problem.

The discussion so far has investigated the conditions under which equilibrium development is less dense than optimal development. It is also of interest to investigate the magnitude of the welfare loss associated with this divergence. Suppose that low density development is observed 
for a neighborhood which lies in regions II or IV, where high density development is optimal. The rent generated by such a neighborhood is simply,

$$
W^{L}=2 N p_{y}
$$

the sum of payments collected by landowners. The rent generated by the corresponding unobserved high density neighborhood is,

$$
W^{H}=2 N\left(w-u_{\theta}-t_{W}\right)-F .
$$

If we recall from propositions 2 and 5 that in a low density equilibrium $p_{y}=\frac{1}{2}\left(w-u_{\theta}-t_{D}+\delta\right)$ then it follows that $W^{H}-W^{L}$ is increasing in $w-u_{\theta}$ for fixed $\delta$. Thus, in figure 4 , for given $\delta$, $W^{H}-W^{L}$ is largest at the eastern boundary of region IV, where $w-u_{\theta}=\delta+t_{D}$, i.e., at the largest value of $w-u_{\theta}$ where low density can occur in equilibrium when high density is optimal. A little algebra shows that at this boundary, $p_{y}=0$, so

$$
\begin{aligned}
W^{H}-W^{L} & =W^{H} \\
& =2 N\left(w-u_{\theta}-t_{W}\right)-F \\
& =2 N\left(\delta+t_{D}-t_{W}\right)-F \\
& >2 N \delta+N q-F .
\end{aligned}
$$

where the last line follows from the assumption that $t_{W}+q<t_{D}$. In sum, the welfare loss from inefficient low density development can be larger than number of parcels in the neighborhood multiplied by the open space bonus, plus the profits of the local retailer. Since people often appear to assign a high value to a larger yard, in principal, this could be a large quantity. Thus, it is probable that the inefficiency studied here is economically important in some neighborhoods.

There are a number of possible solutions to the inefficiencies identified here. The creation of land owners who are large relative to $Y$, or the presence of local zoning authorities whose jurisdictions are large relative to $Y$ can insure that the coordination problem is resolved optimally. A tax on large lots can also be effective. If the purchase of second parcels is taxed just highly enough that immigrants wishing to consolidate single lots into double lots find it uneconomic to do so, then in both regions III and IV, the only equilibrium which survives is one in which the neighborhood is settled at high density and the local retailer enters.

A free rider problem emerges in regions I and II. Given the presence of a local retailer, the value of single lot to an immigrant is less than the value of a second lot. Thus, given a local retailer immigrants prefer to locate in $Y$ at high density to $\theta$. However, given a local retailer they also prefer to occupy a double lot to a single lot, so that immigrants occupying single lots are displaced by immigrants occupying double lots. Put another way, immigrants buying double lots free ride on the fact that other immigrants facilitate the entry of the local retailer by living on single rather than double lots. The policy responses to this are the same as for other public goods problems. Either tax 'bad' behavior, or subsidize 'good' behavior. In this case, this means taxing the acquisition of a second parcel, or subsidizing immigrants on single lots.

A third problem also contributes to the divergence between optimum and equilibrium in regions I and II. In equilibrium immigrants make their location decisions on the basis the full retail 
price of retail services, $t_{W}+q$. The optimal development pattern is determined by the magnitude of the fixed cost and the difference between travel costs to local and remote retailers, but not $q$. Inspection of figure 4 shows that if $q$ decreases to $\frac{F}{2 N}$ then the size of regions I and II also decreases. A subsidy for the purchase of local retail services also appears to resolve this problem. Alternately, the condition $q=\frac{F}{2 N}$ is the zero profit condition for the local retailer, a possible outcome for some models of monopoly pricing. Thus, this problem will not emerge under market structures that insure that the local retailer collects no monopoly rent.

It is tempting to contemplate restrictions on the scale or presence of remote retailing as a possible solution to possible gap between equilibrium and optimum development. However, on the basis of the current analysis it is not possible to argue for or against such restriction. In particular, the optimality of this strategy will depend crucially on the extent of returns to scale in the local and remote retail sectors, an issue that the current analysis deliberately ignores. With this said, it is clear that restrictions on remote retailing are at best an indirect solution to the possibility of inefficiently low residential densities. A tax on large lots or a subsidy for small lots addresses the problem much more directly.

\section{An empirical test for efficiency}

Given that vacant and low density development can be either optimal or suboptimal, it is of interest to be able to distinguish optimal from suboptimal residential development.

By inspection of figure 4 inefficiently low densities can occur in regions II and IV. In these regions the following two inequalities hold,

$$
\delta+t_{D}>w-u_{\theta}>\delta+\left(2 t_{W}+\frac{F}{N}-t_{D}\right)
$$

and

$$
w-u_{\theta}+\delta>t_{D}
$$

Conditional on observing low density development, from propositions 3 and 5, we have that the price of a parcel in these regions is $p_{y}=\frac{1}{2}\left(w-u_{\theta}-t_{D}+\delta\right)$. A little algebra allows us to rewrite the two equations above in terms of this observed price of a parcel,

$$
\delta>p_{y}>\delta+t_{W}+\frac{F}{2 N}-t_{D}
$$

and

$$
p_{y}>0
$$

In words, if we observe low density development then this development is inefficient if the price of a parcel is less than $\delta$, but larger than $\delta$ minus the difference between the cost of providing retail services remotely rather than locally.

Similarly, inspection of figure 4 shows that inefficiently vacant land can occur in regions I and III. In these regions the following inequality holds,

$$
w-u_{\theta}>t_{W}+\frac{F}{2 N} .
$$




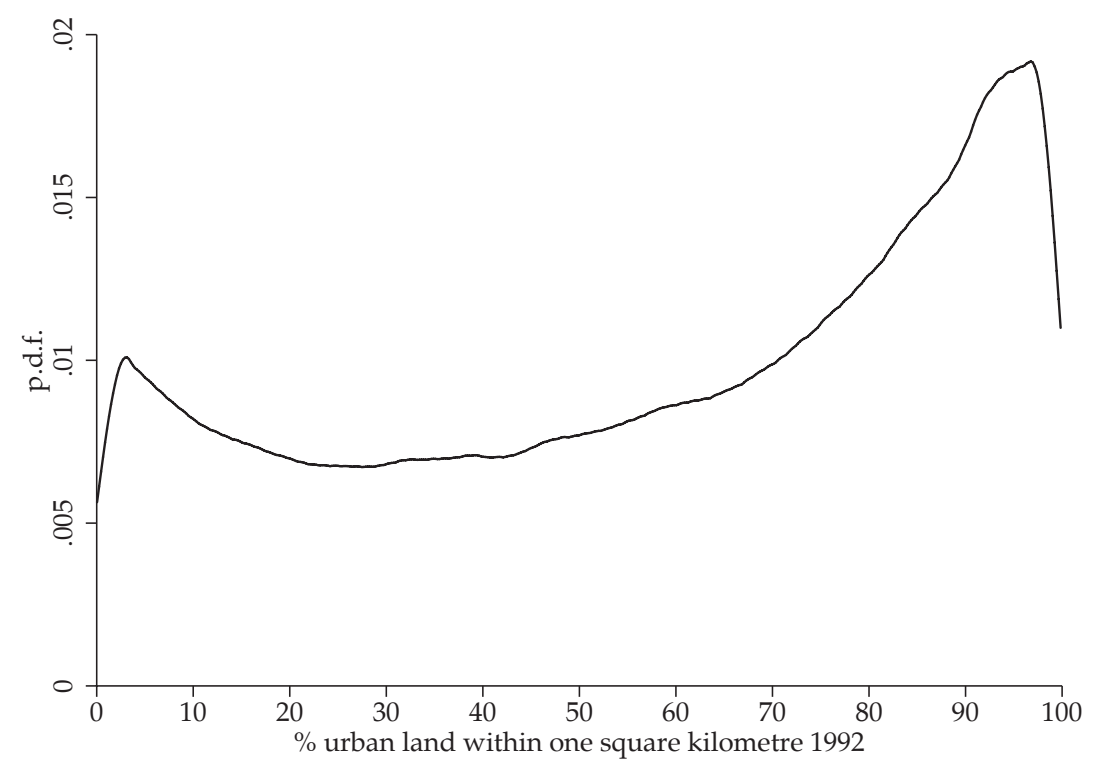

Figure 5. Probability density function of population density across areas of different intensity of development.

That is, a parcel that is vacant in equilibrium is optimally developed as high density housing if immigrants can locate in the neighborhood in question, shop locally, and still be better off than they would be in the alternative city.

While each of these inequalities is clearly difficult to estimate empirically, all of the quantities involved are, at least in principal, subject to observation. Thus, it should be possible to distinguish inefficient low density development from efficient low density development.

\section{Some suggestive empirical evidence}

One of the predictions of the model developed here is that there will be two types of neighborhoods, those populated at high densities and those populated at low densities. Neighborhoods with intermediate densities cannot occur in equilibrium.

Figure 5, which is based on the analysis and data in Burchfield et al. (5), presents some evidence consistent with this prediction. The figure is based on a map of the continental US derived from 1992 satellite imagery. Burchfield et al. (5) overlay the whole of the continental US with a regular grid whose cells are approximately one kilometer square. For each such cell they calculate the share of its area which, according to the satellite, is in residential use. The horizontal axis of figure 5 describes the share of such a grid cell that is in residential use. The vertical axis gives the share of US population from the 1990 us census. The solid line in the figure is a p.d.f. describing the distribution of population across regions which are developed at different densities.

We see that this p.d.f. is bimodal. People are relatively more likely to live in low density or high density neighborhoods. People are less likely to live at intermediate densities. While other possible explanations for this finding are possible, e.g., Harrison and Kain (9), this graph is clearly 
consistent with the predictions of the game of residential and retail development analyzed here: neighborhoods tend to be occupied at high densities or low densities, not at intermediate densities.

\section{Conclusions}

The results of this analysis are as follows. Only three residential development patterns are possible in equilibrium, 'vacant', 'high density with a local retailer' and 'low density without a local retailer'. Intermediate types of neighborhood cannot occur in equilibrium. There is some suggestive empirical evidence in support of this conclusion.

The types of neighborhoods in which these different patterns occur are intuitive. Vacant land occurs in unattractive places. Low density development occurs where the large lot bonus is large relative to the other components of the value of the land. High density development with a local retailer occurs where the large lot bonus is not large relative to the other component of land value, and this other component is itself large. Interestingly, for intermediate parameter values multiple equilibria are possible: immigrants will occupy a neighborhood at high density if and only if a local retailer also enters.

A normative analysis of this model shows that equilibrium and optimal patterns of development do not always coincide and, when they diverge, optimal development is always at a higher density than equilibrium development. There are three reasons for this divergence. First, in parts of the parameter space where multiple equilibria are possible, immigrants may fail to coordinate on the socially optimal equilibrium. Second, residential location choices may be subject to a free rider problem. This problem arises when immigrants consolidate single lots into double lots without regard for the fact that this action may make the local retailer unprofitable. Third, immigrants respond to the market price of local retail services rather than the social price. If the local retailer is able to exercise monopoly power to price retail services above their average cost, this can cause immigrants to not occupy a neighborhood at high density when this is optimal.

In every case, the divergence between optimal and equilibrium development is driven by immigrants who have an incentive consolidate single lots into double lots when it is optimal to occupy single lots. Thus, the policy response to these problems is clear. The planner should tax the acquisition of large lots or subsidize people who live on small lots. Alternately, the presence landowners or zoning authorities that are large relative to a neighborhood should also be effective.

It is interesting to note that the divergence between optimal and equilibrium development does not arise from the factors usually listed as precursors to urban sprawl, e.g., failure to price roads or infrastructure correctly. Indeed, in the model I have analyzed, private and social transportation costs coincide and there are no marginal costs of infrastructure. Clearly, if transportation and infrastructure are not correctly priced this will exacerbate other inefficiencies that arise in this model.

It is worthwhile to note that the model of retail and residential development analyzed here may also be useful in the analysis of local public goods for which there are increasing returns to scale, e.g., schools, police stations, parks. The principal difference between the problem of retail location 
and the problem of public good location is that retail services are financed by market transactions, while local public goods are financed by taxes.

Curiously, this analysis seems to confirm the view taken by both urban economists and by antisprawl activists. This model clearly indicates the possibility for equilibrium development patterns that are more than marginally different from the optimum. However, these fundamentally wrong development patterns can be avoided with a change in marginal incentives, a tax on the acquisition of large lots. With this said, this tax is not one that economists have considered previously.

Finally, it is worthwhile to contrast the results obtained here with those obtained in Turner (16). In this earlier paper I examine the way that residential land is organized when individuals have a taste for nearby public open space. In this environment a competitive equilibrium is 'too dense' because in a market equilibrium individuals do not account for the harm they cause their neighbors by occupying open spaces. The policy response to this problem requires regulation to preserve open space in certain regions of a city. Loosely, the current paper considers the implications of increasing returns to population density in an environment where individuals derive utility from large private land holdings and finds that competitive equilibrium under provides density. Both effects are probably at work in reality and combining the two results suggests that equilibrium cities will tend to have too little public open space, too much private land and too few shops near residential neighborhoods.

\section{Appendix: Proofs:}

Proposition 1 If $w-u_{\theta}-\left(t_{W}+q\right)<\delta$ and $w-t_{D}+\delta<u_{\theta}$ then a pattern of retail and residential location is a subgame perfect equilibrium outcome if and only if all immigrants choose $\theta$ and the local retailer does not enter.

Proof: (Necessity) Suppose the local retailer enters and $N^{\prime}<\frac{F}{q}$ immigrants locate in $Y$. Then the local retailer's profits are $\pi=N^{\prime} q-F$. This is less than zero by hypothesis, so the local retailer exits. Suppose the local retailer enters and $N^{\prime \prime} \geq \frac{F}{q}$. Since $\frac{F}{q}$ is larger that $N$, at least two immigrants must occupy single lots, say $j$ and $j^{\prime}$. In equilibrium $u_{j}=w-p_{y_{j}}-\left(t_{W}+q\right) \geq u_{\theta}$ or $j$ deviates to $\theta$. This implies that $p_{y_{j}} \leq w-u_{\theta}-\left(t_{W}+q\right)$. If landlord $y_{j}$ deviates to $p_{y_{j}}^{\prime} \in\left(w-u_{\theta}-\left(t_{W}+q\right), \delta\right)$ then, in the second stage location game, immigrant $j$ can deviate to $\theta$ and $j^{\prime}$ is better off deviating to $y_{j}$ for a change in payoff $\Delta u_{j^{\prime}}=\delta-p_{y_{j}}^{\prime}>0$. Thus there is no equilibrium where the local retailer enters.

Suppose the local retailer does not enter and some immigrant $j$ locates in $Y$. Then $u_{j} \leq w-t_{D}+$ $\delta$. But by hypothesis this is less than $u_{\theta}$. Thus there is no equilibrium where the local retailer does not enter and any immigrants locate in $Y$.

(Sufficiency) Say all immigrants choose $\theta$ and the local retailer does not enter. If the local retailer deviates and enters then its profits are $-F$ instead of zero. If immigrant $j$ deviates to $Y$ then $u_{j} \leq$ $w-t_{D}+\delta$. This is less than $u_{\theta}$ by hypothesis. 
Proposition 2 If $w-u_{\theta}-\left(t_{W}+q\right)<\delta$ and $w+\delta-t_{D}>u_{\theta}$ then an outcome of the retail and residential development game is a subgame perfect equilibrium if and only if $N$ immigrants occupy double lots in $Y$, the price of all lots is $p_{y}=\frac{1}{2}\left(w-u_{\theta}-t_{D}+\delta\right)$, and the local retailer does not enter.

(Necessity) Say local retailer enters and $N^{\prime}<\frac{F}{q}$ immigrants locate in $Y$. Then $\pi \leq N^{\prime} q-F<0$ so the local retailer exits. Suppose the local retailer enters and $N^{\prime \prime} \geq \frac{F}{q}$ immigrants locate in $Y$. Since $\frac{F}{q}>N$ at least two immigrants, say $j$ and $j^{\prime}$, occupy single lots. It follows that $u_{j}=$ $w-p_{y_{j}}-\left(t_{W}+q\right) \geq u_{\theta}$ so that $p_{y_{j}} \leq w-u_{\theta}-\left(t_{W}+q\right)$. This is less than $\delta$ by hypothesis. If landlord $y_{j}$ deviates to $p_{y_{j}}^{\prime} \in\left(w-u_{\theta}-\left(t_{W}+q\right), \delta\right)$ then in the second stage location game $j$ is better off deviating to $\theta$ and $j^{\prime}$ occupies $y_{j}$ as a second lot for a change in utility, $\Delta u_{j^{\prime}}=\delta-p_{y_{j}}^{\prime}>0$. Thus there is no equilibrium in which the local retailer enters.

Suppose the local retailer does not enter. If some immigrant $j$ occupies a single lot in equilibrium, then $u_{j}=w-t_{D}-p_{y_{j}} \geq u_{\theta}$. This implies that $w-t_{d}-u_{\theta} \geq p_{y_{j}}$. Since $\|Y\|$ is even, either there is another immigrant $j^{\prime}$ occupying a single lot in $Y$, or there is a vacant lot in $Y$. Since vacant lots are assumed to have price zero in any equilibrium, if there is a vacant lot, then $j$ can deviate to occupy it for a change in utility $\delta$. If there is another immigrant $j^{\prime}$ occupying a single lot. Then, if landlord $y_{j}$ deviates to $p_{y_{j}}^{\prime} \in\left(w-u_{\theta}-\left(t_{W}+q\right), \delta\right)$, in the second stage location game, immigrant $j$ is better off deviating to $\theta$ and $j^{\prime}$ is better off occupying $y_{j}$ as a second lot. Thus there is no equilibrium where the local retailer does not enter and an immigrant occupies a just one parcel.

Suppose the local retailer does not enter and there is an unoccupied parcel $y$ in $Y$. Since no immigrant occupies a single lot and $\|Y\|$ is even, there must be a second vacant parcel $y^{\prime}$. By assumption $p_{y}=p_{y^{\prime}}=0$, so if immigrant $j$ deviates from $\theta$ to occupy $\left\{y, y^{\prime}\right\}$ then $u_{j}=w-t_{D}+$ $\delta>u_{\theta}$. Thus, the only possible equilibrium occurs when the local retailer does not enter and $N$ immigrants occupy double lots in $Y$.

Suppose $N$ immigrants occupy double lots in $Y$ and the local retailer does not enter. Then for each immigrant we must have $u_{j}=w-\left(p_{y_{j}}+p_{y_{j}^{\prime}}\right)-t_{D}+\delta=u_{\theta}$. If $u_{j}<u_{\theta}$ then $j$ deviates to $\theta$. If $u_{j}>u_{\theta}$ then landlord $y_{j}$ can deviate to a higher price without creating an incentive for immigrant $j$ to deviate. It follows that, for each $j$ the price of at least one of his two lots, say $y_{j}$, satisfies $p_{y_{j}} \geq \frac{1}{2}\left(w-u_{\theta}-t_{D}+\delta\right)$. Suppose that for some $j^{\prime}, p_{y_{j^{\prime}}^{\prime}}<\frac{1}{2}\left(w-u_{\theta}-t_{D}+\delta\right)$. Then landlord $y_{j^{\prime}}^{\prime}$ can deviate to $p_{y_{j^{\prime}}^{\prime}}^{\prime} \in\left(p_{y_{j^{\prime}}^{\prime}} \frac{1}{2}\left(w-u_{\theta}-t_{D}+\delta\right)\right)$. This deviation causes immigrant $j^{\prime}$ to deviate to $\theta$ in the second stage location game, and any of the other $N-1$ immigrants in $Y$ to exchange their high priced lot for $y_{j^{\prime}}^{\prime}$. Thus the only possible equilibrium occurs when the local retailer does not enter, $N$ immigrants occupy double lots in $Y$, and $p_{y}=\frac{1}{2}\left(w-u_{\theta}-t_{D}+\delta\right)$ for all $y$ in $Y$.

(Sufficient) Say the local retailer does not enter, $N$ immigrants occupy double lots in $Y$, and $p_{y}=$ $\frac{1}{2}\left(w-u_{\theta}-t_{D}+\delta\right)$ for all $y$ in $Y$. If the local retailer enters then its profits decrease to $N q-F<0$, from 0 . All immigrants are indifferent between their double lot and deviating to $\theta$. An immigrant $j$ deviating to a single lot experiences a change in utility $\Delta u_{j}=p_{y}-\delta=\frac{1}{2}\left(w-u_{\theta}-t_{D}+\delta\right)-\delta$. Since $w-u_{\theta}-t_{D}<w-u_{\theta}-\left(t_{W}+q\right)$ which is less than $\delta$ by hypothesis, it follows that $\Delta u_{j}<0$. Landlords cannot rationally deviate to a lower price, and deviating to a higher price creates an incentive for their occupying immigrant to deviate to $\theta$, not to be replaced. 
Proposition 3 If $w-u_{\theta}>\delta+\left(t_{W}+q\right)$ and $w-u_{\theta}+\delta<t_{D}$ then an outcome of the retail and residential development game is a subgame perfect equilibrium if and only if:

1. All immigrants choose $\theta$ and the local retailer does not enter, or,

2. $2 N$ immigrants occupy single lots in $Y, p_{y}=w-u_{\theta}-\left(t_{W}+q\right)$ for all $y$ in $Y$, and the local retailer enters.

Proof: (Necessity[1]) Say the local retailer does not enter and some immigrant occupies a location in $Y$. Then $u_{j} \leq w-t_{D}+\delta$. Therefore, by hypothesis, $u_{j}<u_{\theta}$, so immigrant $j$ deviates to $\theta$. Thus, if the local retailer does not enter, there is no equilibrium where immigrants locate in $Y$.

(Sufficiency[1]) Say the local retailer does not enter and all immigrants choose $\theta$. If the local retailer deviates and enters its profits decrease to $-F$ from 0 . If an immigrant $j$ deviates and locates in $Y$ then $u_{j} \leq w-t_{D}+\delta$, which is less than $u_{\theta}$ by hypothesis.

(Necessity[2]) Say the local retailer enters and a lot $y$ in $Y$ is vacant. Then immigrant $j$ can deviate from $\theta$ to $y$ for a payoff $u_{j}=w-\left(t_{W}+q\right)$ which is greater than $u_{\theta}$ since $w-\left(t_{W}+q\right)>$ $u_{\theta}+\delta$ by hypothesis. Thus no lot in $Y$ is vacant. Say the local retailer enters and some immigrant $j$ occupies a double lot $\left\{y_{j}, y_{j}^{\prime}\right\}$. Then $p_{y_{j}}$ and $p_{y_{j}^{\prime}} \leq \delta$ or $j$ deviates to a single lot. By hypothesis, $\left(\delta, w-u_{\theta}-\left(t_{W}+q\right)\right)$ is not empty. Thus landlord $y_{j}$ can deviate to $p_{y_{j}}^{\prime} \in\left(\delta, w-u_{\theta}-\left(t_{W}+q\right)\right)$. In the second stage location game, immigrant $j$ responds by deviating to a single lot $y_{j}^{\prime}$ or $\theta$, and some immigrant $j^{\prime}$ can deviate from $\theta$ to $y_{j}$ for a payoff $u_{j^{\prime}}=w-p_{y_{j}}^{\prime}-\left(t_{W}+q\right)>u_{\theta}$. Thus, any equilibrium where the local retailer enters equilibrium requires that $2 \mathrm{~N}$ immigrants occupy single lots in $Y$.

Suppose the local retailer enters and $2 N$ immigrants occupy single lots in $Y$. Say $p_{y}<w-u_{\theta}-$ $\left(t_{W}+q\right)$ for some $y_{j}$. Then landlord $y_{j}$ can increase $p_{y_{j}}$ without giving $j$ an incentive to deviate. Conversely, if $p_{y}>w-u_{\theta}-\left(t_{W}+q\right)$, then $u_{j}<u_{\theta}$ and $j$ deviates to $\theta$.

(Sufficiency[2]) Say the local retailer enters, $2 N$ immigrants occupy $Y$, and $p_{y}=w-u_{\theta}-\left(t_{W}+\right.$ q) for all $y$ in $Y$. If the local retailer exits then its profits decrease to zero from $2 N q-F>0$. Immigrants are indifferent between their double lot in $Y$ and $\theta$. Deviating to a single lot results in a change in payoff of $\delta-p_{y}=\delta-\left(w-u_{\theta}-\left(t_{W}+q\right)\right)$ which is negative by hypothesis. Landlords are worse off lowering prices, and insure that their parcel is less attractive than $\theta$ by raising them.

Proposition 4 If $w-u_{\theta}-\delta>t_{D}$ then an outcome of the retail and residential development game is a subgame perfect equilibrium if and only if $2 \mathrm{~N}$ immigrants occupy single lots in $Y, p_{y}=w-u_{\theta}-\left(t_{W}+q\right)$ for all $y$ in $Y$, and the local retailer enters.

Proof: (Necessity) Say the local retailer does not enter and $y$ in $Y$ is vacant. Some immigrant $j$ can deviate from $\theta$ to $y$ for a payoff of $u_{j}=w-t_{D}$. Since $w-u_{\theta}-\delta>t_{D}$ by hypothesis, $w-t_{D}>u_{\theta}$ follows. Thus there are no vacant parcels in $Y$ in any equilibrium when the local retailer does not enter.

Say the local retailer does not enter and $2 \mathrm{~N}$ immigrants locate on single lots in $Y$. Then the local retailer can enter and increase its profits. Thus, in any equilibrium where the local retailer does 
not enter, all lots in $Y$ must be occupied, and some immigrant $j$ in $Y$ must occupy a double lot, say $\left\{y_{j}, y^{\prime}{ }_{j}\right\}$. It follows that $p_{y_{j}}$ and $p_{y^{\prime}} \leq \delta$ or $j$ deviates to a single lot. By hypothesis $\left(\delta, w-u_{\theta}-\delta\right)$ is not empty. Thus landlord $y_{j}$ can deviate to $p_{y_{j}}^{\prime} \in\left(\delta, w-u_{\theta}-t_{D}\right)$. In the second stage location game, immigrant $j$ is better off deviating from $\left\{y_{j}, y^{\prime}{ }_{j}\right\}$ to $\theta$, and some immigrant $j^{\prime}$ deviates from $\theta$ to $y_{j}$ for a payoff $u_{j^{\prime}}=w-p_{y_{j}}^{\prime}-t_{D}>u_{\theta}$. Thus, if the local retailer does not enter, $Y$ contains no vacant parcels in equilibrium.

Say the local retailer enters and some lot in $Y$ is vacant. Then $j$ can deviate from $\theta$ to $y$ for payoff $u_{j}=w-\left(t_{W}+q\right)$. Since $w-\left(t_{W}+q\right)>w-t_{D}>w-t_{D}-\delta>u_{\theta}$, this deviation is rational. Say the local retailer enters and some immigrant $j$ occupies a double lot $\left\{y_{j}, y_{j}^{\prime}\right\}$. Then $p_{y_{j}}$ and $p_{y_{j}^{\prime}} \leq \delta$ or $j$ deviates to a single lot. By hypothesis, $\left(\delta, w-u_{\theta}-t_{D}\right)$ is not empty. Thus landlord $y_{j}$ can deviate to $p_{y_{j}}^{\prime} \in\left(\delta, w-u_{\theta}-t_{D}\right)$. In the second stage location game, immigrant $j$ is better off deviating to $\theta$, and some immigrant $j^{\prime}$ rationally deviates from $\theta$ to $y_{j}$ for a payoff $u_{j^{\prime}}=w-p_{y_{j}}^{\prime}-t_{D}>u_{\theta}$.

Now say $2 N$ immigrants occupy single lots in $Y$, the local retailer enters, and $p_{y}<w-u_{\theta}-$ $\left(t_{W}+q\right)$ for some $y_{j}$. Then landlord $y_{j}$ can increase $p_{y_{j}}$ without giving $j$ an incentive to deviate. Conversely, if $p_{y}>w-u_{\theta}-\left(t_{W}+q\right)$, then $u_{j}<u_{\theta}$ and $j$ deviates to $\theta$.

(Sufficiency) Say the local retailer enters, $2 N$ immigrants occupy single lots in $Y$, and $p_{y}=w-u_{\theta}-\left(t_{W}+q\right)$ for all $y$ in $Y$. If the local retailer exits it profits decrease to zero from $2 N q-F>0$. Immigrants are indifferent between their single lots in $Y$ and $\theta$. Landlords are worse off lowering prices, and insure that their parcel is less attractive than $\theta$ by raising them.

Proposition 5 If $w-u_{\theta}-t_{D}<\delta, w-u_{\theta}-\left(t_{W}+q\right)>\delta$ and $w-u_{\theta}+t_{D}>\delta$ then an outcome of the retail and residential development game is a subgame perfect equilibrium if and only if:

1. $N$ immigrants occupy double lots in $Y, p_{y}=\frac{1}{2}\left(w-u_{\theta}-t_{D}+\delta\right)$ for all $y$ in $Y$, and the local retailer does not enter, or,

2. $2 N$ immigrants occupy single lots in $Y, p_{y}=w-u_{\theta}-\left(t_{W}+q\right)$ for all $y$ in $Y$, and the local retailer enters.

Proof: (Necessity[1]) Say the local retailer does not enter and some immigrant $j$ occupies a single lot $y$ in $Y$. Then $u_{j}=w-p_{y_{j}}-t_{D} \geq u_{\theta}$ which implies that $p_{y_{j}} \leq w-u_{\theta}-t_{D}$. Thus, by hypothesis, $p_{y}<\delta$. Since $\|Y\|$ even, if immigrant $j$ occupies a single lot then either there is another vacant lot or another immigrant $j^{\prime}$ occupies a single lot in $Y$. If landlord $y_{j}$ deviates to $p_{y_{j}}^{\prime} \in\left(w-u_{\theta}-t_{D}, \delta\right)$ then immigrant $j$ deviates to $\theta$ and, either, immigrant $j^{\prime}$ occupies $y_{j}$ as a second lot, or an immigrant from $\theta$ occupies $y_{j}$ and the vacant lot. Thus, if the local retailer does not enter, no immigrant occupies a single lot in $Y$.

Say the local retailer does not enter and some lot in $Y$ is vacant. Since no immigrant occupies a single lot and $\|Y\|$ is even, there must be two vacant lots $\left\{y, y^{\prime}\right\}$ in $Y$. If immigrant $j$ deviates from $\theta$ to $\left\{y, y^{\prime}\right\}$ then $u_{j}=w-t_{D}+\delta$ which is greater than $u_{\theta}$ by hypothesis. Thus any equilibrium of the retail and residential development game in which the local retailer does not enter, must have $N$ immigrants occupying double lots in $Y$. 
Suppose $N$ immigrants occupy double lots in $Y$ and the local retailer does not enter. Then for each immigrant we must have $u_{j}=w-\left(p_{y_{j}}+p_{y_{j}^{\prime}}\right)-t_{D}+\delta=u_{\theta}$. If $u_{j}<u_{\theta}$ then $j$ deviates to $\theta$. If $u_{j}>u_{\theta}$ then landlord $y_{j}$ can deviate to a higher price without creating an incentive for immigrant $j$ to deviate. It follows that for each $j$ the price of at least one of their two lots, say $y_{j}$, satisfies $p_{y_{j}} \geq \frac{1}{2}\left(w-u_{\theta}-t_{D}+\delta\right)$. Suppose that for some $j^{\prime}, p_{y_{j^{\prime}}^{\prime}}<\frac{1}{2}\left(w-u_{\theta}-t_{D}+\delta\right)$. Then landlord $y_{j^{\prime}}^{\prime}$ can deviate to $p_{y_{j^{\prime}}^{\prime}}^{\prime} \in\left(p_{y_{j^{\prime}}^{\prime}} \frac{1}{2}\left(w-u_{\theta}-t_{D}+\delta\right)\right)$. This deviation causes immigrant $j$ to deviate to $\theta$ in the second stage location game, and any of the other $N-1$ immigrants in $Y$ to exchange their high priced lot for $y_{j}^{\prime}$. Thus the only possible equilibrium occurs when the local retailer does not enter, $N$ immigrants occupy double lots in $Y$, and $p_{y}=\frac{1}{2}\left(w-u_{\theta}-t_{D}+\delta\right)$ for all $y$ in $Y$.

(Sufficiency[1]) Say the local retailer does not enter, $N$ immigrants occupy double lots in $Y$, and $p_{y}=\frac{1}{2}\left(w-u_{\theta}-t_{D}+\delta\right)$ for all $y$ in $Y$. If the local retailer enters its profits decrease to $N q-F<0$, from 0 . All immigrants are indifferent between their double lot and deviating to $\theta$. An immigrant $j$ deviating to a single lot experiences a change in utility $\Delta u_{j}=p_{y}-\delta=\frac{1}{2}\left(w-u_{\theta}-t_{D}+\delta\right)-\delta$. Since $w-u_{\theta}-t_{D}<\delta$ by hypothesis, it follows that $\Delta u_{j}<0$. Landlords cannot rationally deviate to a lower price, and deviating to a higher price creates an incentive for their occupying immigrant to deviate to $\theta$, not to be replaced.

(Necessity[2]) Say the local retailer enters and some location $y$ in $Y$ is vacant. Then immigrant $j$ can deviate from $\theta$ to $y$ for a payoff $u_{j}=w-\left(t_{W}+q\right)$. Since $w-\left(t_{W}+q\right)-\delta>u_{\theta}$ by hypothesis, it follows that $u_{j}>u_{\theta}$. Say the local retailer enters and some immigrant occupies a double lot $\left\{y_{j}, y_{j}^{\prime}\right\}$. It follows that $p_{y_{j}}$ and $p_{y_{j}^{\prime}} \leq \delta$ or $j$ deviates to a single lot. If landlord $y_{j}$ deviates to $p_{y_{j}}^{\prime} \in\left(\delta, w-u_{\theta}-\left(t_{W}+q\right)\right)$ then in the second stage location game, immigrant $j$ is better off deviating from $\left\{y_{j}, y_{j}^{\prime}\right\}$ to $\theta$, and some immigrant $i$ deviates from $\theta$ to $y_{j}$ for a payoff $u_{i}=w-$ $\left(t_{W}+q\right)-p_{y_{j}}^{\prime}>u_{\theta}$. Thus in any equilibrium where the local retailer enters, $2 N$ immigrants must occupy single lots in $Y$.

\section{References}

[1] M. Berliant, H. Konishi, The endogenous formation of a city: population agglomeration and marketplaces in a location-specific production economy, Regional Science and Urban Economics 30 (2000) 289-324.

[2] M. Berliant, M. Fujita, Alonso's discrete population model of land use: Efficient allocations and competitive equilibria, International Economic Review 33 (3) (1992) 535-566.

[3] J. K. Brueckner, Urban Sprawl: Lessons from Urban Economics, Brookings-Wharton Papers on Urban Affairs (2001) 65-97.

[4] J. K. Brueckner, The Structure of Urban Equilibria: A Unified Treatment of the Muth-Mills Model, in: E. S. Mills (Ed), Handbook of Regional and Urban Economics vol. 2, North-Holland, Amsterdam, 1987, pp. 821-845.

[5] M. Burchfield, H. G. Overman, D. Puga, M. A. Turner, Causes of sprawl: A portrait from space, Quarterly Journal of Economics 121 (2) (2006) 587-633. 
[6] D. DiPasquale, W. C. Wheaton Urban economics and real estate markets, Prentice Hall, Englewood Cliffs, 1996.

[7] D. Puga, G. Duranton, Micro-foundations of urban agglomeration economies, in: J.V. Henderson, J. Thisse (Eds), Handbook of Regional and Urban Economics vol 4, North-Holland, Amsterdam, 2004, pp. 2063-2117.

[8] M. Fujita, J. Thisse, Economics of Agglomeration: Cities, Industrial Location, and Regional Growth, Cambridge University Press, Cambridge, 2002.

[9] D. Harrison, J. F. Kain, Cumulative urban growth and urban density functions, Journal of Urban Economics 1 (1) (1974) 61-98.

[10] R. W. Helsley, W. C. Strange, Social interactions and urban spatial structure, Processed, University of Toronto (2005).

[11] J. V. Henderson, A. Mitra, The new urban landscape: Developers and edge cities, Regional Science and Urban Economics 26 (6) (1996) 613-643.

[12] J. H. Kuntsler, Home from Nowhere, The Atlantic Monthly (September, 1996) 43-66.

[13] A. Mas-Colell, M. Whinston, J. Green, Microeconomic Theory Oxford University Press, NY, 1995.

[14] National Highway Transportation Survey, Changes in the Purpose of Travel Over Time: A snapshot analysis of the National Household Travel Survey, http:/ /nhts.ornl.gov/2001/pub/purposeOverTime.shtml (2001).

[15] S. Scotchmer, Local public goods and clubs, in: A. J. Auerbach, M. Feldstein (Eds.), Handbook of Public Economics vol 4, North-Holland, Amsterdam, 2002, pp. 1997-2042.

[16] M. A. Turner, Landscape Preferences and Patterns of Residential Development, Journal of Urban Economics 57 (1) (2005) 19-54 